\title{
Application of endoscopic tattooing in intraoperative localization of colon tumours and sentinel lymph nodes
}

\author{
Norbert Nowak ${ }^{1, A-D, F \oplus}$, Jacek Dziedzic ${ }^{1, A-D \oplus}$, Kamil Nurczyk ${ }^{2, D-F} \oplus$, Artur Zakościelny ${ }^{1, A-C \oplus}$, \\ Paweł Bury ${ }^{1, A-C} \oplus$, Witold Zgodziński ${ }^{1, A-C, E-F \oplus}$, Krzysztof Zinkiewicz ${ }^{1, A-C, E-F \oplus}$ \\ ${ }^{1}$ Diagnostic and Therapeutic Endoscopy Unit, Medical University, Lublin, Poland \\ 2 2nd Department of General Surgery, Medical University, Lublin, Poland \\ A - Research concept and design, B - Collection and/or assembly of data, C - Data analysis and interpretation, \\ $D$ - Writing the article, $E$ - Critical revision of the article, $F$ - Final approval of article
}

Nowak N, Dziedzic J, Nurczyk K, Zakościelny A, Bury P, Zgodziński W, Zinkiewicz K. Application of endoscopic tattooing in intraoperative localization of colon tumors and sentinel lymph nodes. J Pre-Clin Clin Res. 2020; 14(4): 134-138. doi: 10.26444/jpccr/128226

\begin{abstract}
Introduction. Minimally invasive techniques in colorectal surgery have become increasingly popular and are considered a standard of care in most surgical cenres. Locating the tumour during laparoscopic procedure can be technically challenging. Incorrect localization of the primary lesion may lead to a non-radical resection margin. The technique of endoscopic tattooing (ET) prior to surgery or endoscopic treatment is considered a useful tool. Various dyes can be used for this purpose, such as: Indian ink, methylene blue, indigocarmine, toluidine blue, isosulfan blue, haematoxylin and eosin, indoxin green. This procedure is recommended by international scientific societies (ASGE and ESGE).

Objective. The purpose of the study is to review the current literature on the use of ET in large intestine tumour lesions. Materials and method. A MEDLINE literature search of English language articles addressing the use of ET to enable intraoperative tumour localization in colorectal surgery was performed to evaluate and summarize the feasibility of this technique.

Results. The use of ET enables the easy and safe localization of colorectal tumurs during minimally invasive colorectal procedures. The percentage of complications is insignificant.

Conclusions. The available literature proves the safety and benefits of using the ET prior to surgical or endoscopic treatment. ASGE and ESGE recommend the use of ET in marking tumours before surgical treatment, and the area after endoscopic resection for further evaluation.
\end{abstract}

\section{Key words}

colorectal cancer, surgical treatment, Endoscopy, endoscopic tattoo

\section{INTRODUCTION}

Minimally invasive techniques in colorectal surgery have become increasingly popular and are considered a standard of care in most surgical centres. The introduction of laparoscopic and robotic techniques to common use allows achievement better outcomes[1]. However, the intraoperative localization of small colorectal tumours still remains technically challenging. Difficulties in locating the lesion may lead to an inappropriate range of intestinal resection. One of the ways to facilitate accurate tumour localization is to perform an endoscopic tattooing (ET) procedure prior to surgery. This technique was first described in 1975 by Ponsky et al. [2]. In their recent guidelines the European Society of Gastrointestinal Endoscopy (ESGE) recommends marking the lesion prior to surgical or endoscopic treatment [3]. The use of endoscopic tattooing enables the staining of the tumour area and lymph nodes. Other imaging methods allow for staging the disease and for the treatment of qualification. The endoscopic tattoo affects the type of surgery, the extent of the bowel resection and the use of sparing treatment, and increases the intraoperative comfort of the surgeon and

Address for correspondence: Norbert Nowak, Diagnostic and Therapeutic Endoscopy Unit, Medical University of Lublin, Staszica 16, 20-081, Lublin, Poland E-mail: norbertt.nowak@gmail.com

Received: 24.06.2020; accepted: 07.10.2020; first published: 03.11.2020 the safety of the patient. However, several studies indicate that ET are not always effective $[1,4,5]$. According to this data, ET may be inaccurate in about $7 \%$ of patients $[3,4]$ or even not visible in $15-31 \%$ of cases $[1,4]$. According to several studies, during the post-operative histopathological examination, the presence of dye in the tumour area has been confirmed in only $76 \%$ of patients after ET $[1,4,5]$. Various substances can be used for ET, such as: Indian ink, methylene blue, indigocarmine, indocian green (ICG), toluidine blue, isosulfan blue, haematoxylin and eosin. Some of these dyes may be additionally used for identification of the lymphatic system, including the identification of guard lymph nodes, which is essential to achieve radicality of the resection.

\section{OBJECTIVE}

The aim of the review is to evaluate the current literature on endoscopic tattooing. A MEDLINE literature search of English language articles addressing the use of ET to enable intraoperative tumour localization in colorectal surgery was performed to evaluate and summarize the feasibility of this technique. Key words such as 'endoscopic tattoo', 'endoscopic dyes' and the names of each dye were searched for. Data up to May 2019 was analysed. 


\section{MATERIALS AND METHOD}

Application technique. Recommendations from ESGE and the American Society of Gastrointestinal Endoscsopy (ASGE) indicate that performing an ET prior to surgical or endoscopic treatment is an important aspect of the treatment. The ESGE experts recommend the use of ET for any lesion that may undergo surgery or be endoscopically controlled in the future. According to the ASGE guidelines, it is recommended to administer the dye using the 'four-quadrant injection' technique.This is important especially in the determination of colon lesions. In most cases, $0.5-1.0 \mathrm{ml}$ of the substance is injected in each of the four quadrants of the primary lesion [6]. On the other hand, ESGE recommendations advice the administration of dye by 2-3 injections into the region of the tumour. The injection should be made about $3 \mathrm{~cm}$ from the distal side. One injection should be performed in the lesion line and the other on the opposite side [3]. There are two methods of marker administration: conventional and with submucosal bubble formation. In the conventional method, the injection needle should be directed obliquely into the intestinal wall for submucosal dye administration. The technique of marker administration is the 'saline injection test', in which the submucosal layer is determined by means a saline injection by the formation of a submucosal follicle. The saline syringe is then replaced by an ink syringe and the dye is injected. Finally, the saline is re-injected to empty the ink contained in the injection needle. In the study by Fu et al., [7], where this technique was used in 55 patient, identification of the intra-operative lesion was more effective than in the conventional technique (98\% vs $86.1 \%, \mathrm{p}=.034)$. The efficacy and safety of this method of administration was also demonstrated in studies for Spot dye [6, 7]. A twostage variant of this technique is also describe, in which a salt solution is first injected to form a submucosal bubble. This is followed by separate puncture of the bubble with a needle containing Indian ink, and the injection of a small amount of dye [8]. Injection of a small amount of marker at the puncture site results in smaller and more precise tattoos without wide staining of surrounding tissues.

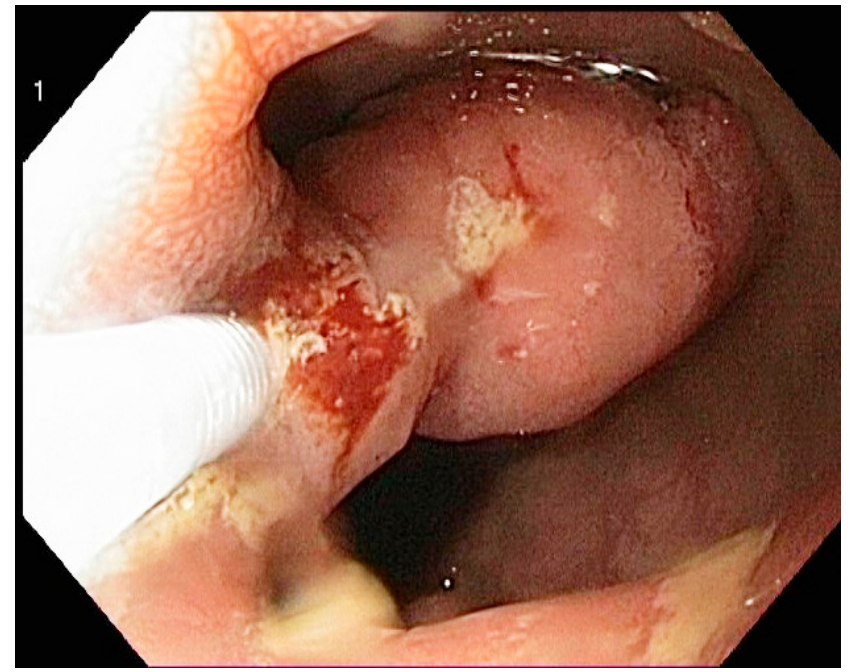

Figure 2. Endoscopic injection of dye

Dyes. Various dyes can be used to perform an endoscopic tattoo. The most commonly used are: Indian ink, methylene blue, indigocarmine, toluidine blue, isosulfan blue, haematoxylin and eosin or indocian green.

Indian ink. This dye is in use since the 1970s [9] and is one of the most popular for endoscopic tattooing. It consists of a colloidal suspension of carbon particle in the solution of organic or non-organic substances. It may contain additional substances such as: ethylene glycol, phenol or gelatin. Although these compounds may cause inflammatory reactions [6] no serious complications in the form of fever, infection or histopathological changes in the collected tissue material have been observed [10]. The marker can be identified intraoperatively more than 48 hours after endoscopic injection $[6,11]$. It is usually used to mark neoplastic colorectal tumours or adenomatous polyps before surgical treatment. Indian ink, together with indocyanine green, is also used for preoperative determination of pancreatic proliferative changes, including small neuroendocrine tumours. Dye injections are performed

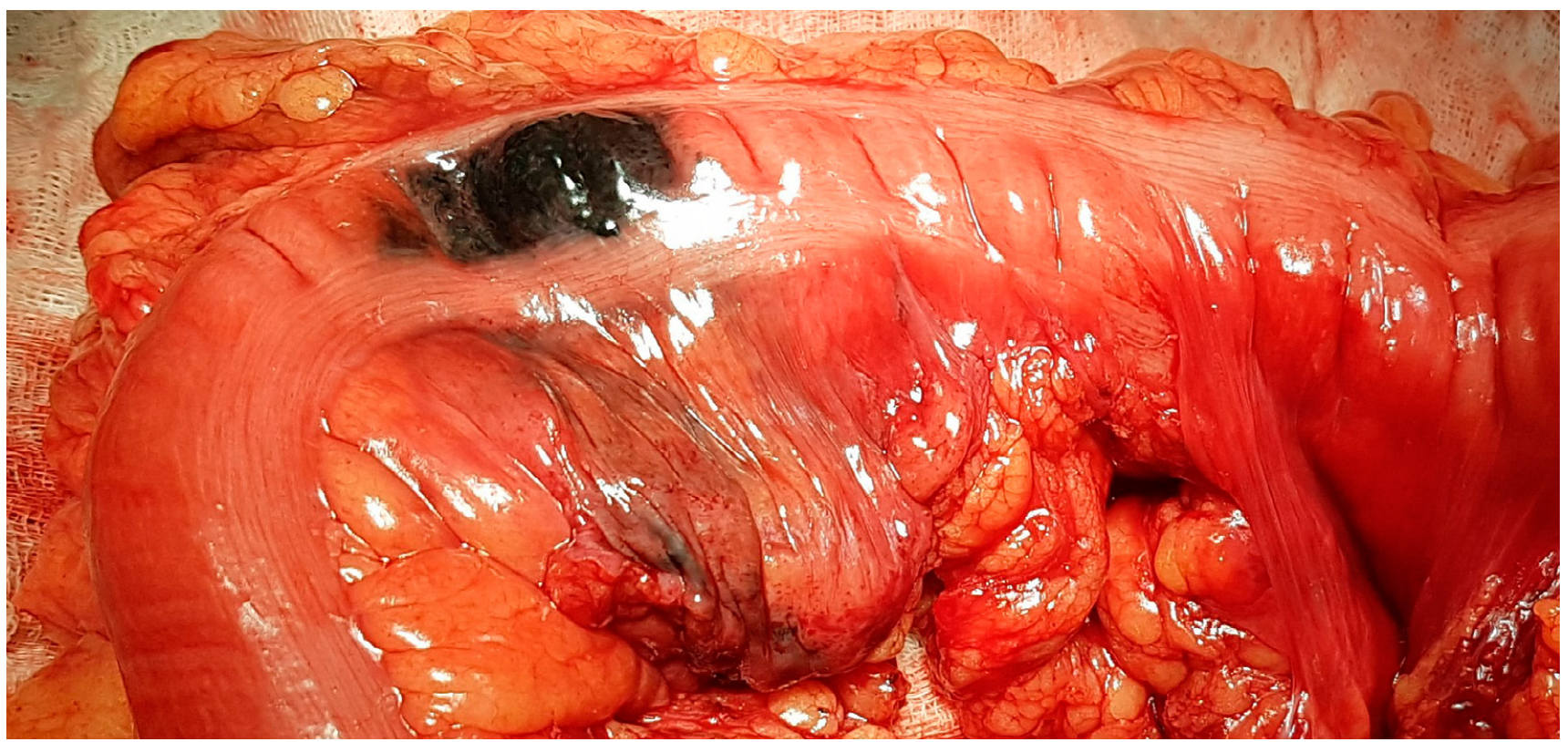

Figure 1. Intraoperative localization of tumor 
under the guidance of endoscopic ultrasonography (EUS) [6, $12-14]$. It is worth mentioning that before using Indian ink, it should be sterilized.

Methylene blue. Methylene blue is an organic dye and a thiazine derivative, first synthesized in 1876 by the German chemist Heinrich Caro [15]. It is often used in injections with saline or adrenaline in endoscopic procedures, such as polypectomy (EP), mucosectomy (EMR) and submucosal dissection (ESD). After injecting into the submucosal layer, it enablesthe correct identification of intestinal wall layers, which reduces the risk of perforation and enables safe removal of a larger piece of tissue. In chromoendoscopy it is used to detect dysplastic changes or other pre-cancerous conditions. It can also be used to detect sentinel lymph nodes [16, 17]. After endoscopic administration, it is absorbed within $24 \mathrm{~h}$.

Indigocarmin. An organic blue compound which is also a dye commonly used in medicine. It is used for endoscopic determination and distinction of flat mucous membrane lesions, such as: unspoiled polyps, shallow epithelial defects or irregularity of mucous membrane surface. It is also used to highlight areas of Barrett's oesophagus before endoscopic biopsy, as well as to detect dysplastic changes and early forms of malignant tumours. Indigocarmine is routinely used in hereditary non-polypoid colorectal cancer (HNPCC), for the detection of flat polyps and in control tests, among others, in the course of inflammatory bowel diseases (IBD) and coeliac disease. One of the dangerous complications of this dye may be increased arterial pressure [18].

Toluidine blue. An organic thiazin dye, also used as a diagnostic dye in chromendoscopy. Toluidine blue dye intensively colours the cells with increased DNA synthesis: malignant cells, erosions, ulcers and inflammatory cells [19].

Isosulfan blue. A synthetic lymphatic imaging agent. The dye is injected into the periphery of the tumour. Isosulfan blue is used to locate the lymphatic system and helps to identify sentinel lymph nodes that are coloured blue during surgery. In the study by Rivet et al., it was used to map lymph nodes in laparoscopic resection in patients with colorectal cancer [20]. Another study proposed the use of isosulfan blue as a safe method for intraoperative lymphatic mapping in patients with colorectal cancer metastases to the liver [21].

Haematoxylin and eosin. These are basic dyes used in histology. Haematoxylin is a blue dye which has a high affinity for DNA phosphate groups, which makes it possible to colour-and-violet alkaline structures (e.g. cell nuclei). Eosin is a yellowish dye that colours acid-absorbent structures (e.g. cytoplasmic proteins) pink. It is also used in the diagnosis of Helicobacter pylori infection, and in the case of endoscopic biopsies of mucosal discolouration [22].

Indocyanine green (ICG). A cyanine fluorescent dye, developed as a dye in photography and first tested in 1957 in the Mayo Clinic for clinical use. Today, ICG has many applications, such as determining cardiac output and liver function. It is also used in angiography, lymph node mapping, lymphatic drainage, detection of early cancer in Barrett's oesophagus, and to assess tissue perfusion and blood supply to gastrointestinal anastomoses [23]. Iodine allergy is a contraindication to ICG [6]. An additional impediment to this imaging method is the need for an infrared camera with a laparoscopic set, to enable detection.

Radioisotope markers. The use of radioisotopes, developed in the 1990s, is one of the modalities of mapping lymph nodes. The most common isotope used is technetium-99 $\left({ }^{99 \mathrm{~m}} \mathrm{Tc}\right)$ in combination with dye. This radioisotope is injected one day before the operation. During the operation, lymph nodes are detected with a gamma probe. This procedure involves transporting the patient to a nuclear medicine facility where the patients are exposed to radiation during the preoperative period.

Spot marker. This is a new commercial product available on the market. The most important ingredient of the dye is a sterile suspension containing fine carbon particles, developed for endoscopic tattooing, approved by the American Food and Drug Administration (FDA). In addition, the marker contains: water, glycerol, polysorbat80, benzyl alcohol, simetone and very fine, high purity carbon molecules. Unlike Indian ink, it does not contain such substances as phenol, shellac or ammonia, which reduces the risk of inflammatory reactions. Additionally, it does not require sterilization before endoscopic administration. The use of this marker for endoscopic tattooing is recommended by the ESGE and $\operatorname{ASGE}[3,6]$.

Sienna $+\bowtie$. The main component of this dye is superparamagnetic iron oxide. After administration to the surrounding area, the primary tumour is identified with the Sentimag probe, both in the lesion and in the sentinel lymph nodes. The identification is expressed by sound and numerical values, which show the amount of marker in the examined tissues. Until now, this marker has been used in breast, endometrial, colorectal and prostate cancer [24-33]. Currently, studies are being conducted on the use of this compound for endoscopic tattooing in patients with stomach and colorectal cancer in vivo.

Complications. There are not many reports of complications after endoscopic tattooing. Studies show that this method is safe. Most of the complications are associated with improperly deep intramural injection outside the digestive tract. So far, single cases of abdominal and abdominal wall abscesses [34-37], focal peritonitis [34, 38], liver abscess [39], and haematoma [40] have been reported. There have also been cases of gastrointestinal bleeding in the form of haematemesis [34], formation of inflammatory pseudotumours [34, 41-42], idiopathic enteritis $[34,43]$, masked enteric infarction $[34,44]$, intestinal perforation $[34,45]$, and mesentery air embolism $[34,46]$. Previously reported complications connected with ET techniques are summarized in Table 1.

\section{DISCUSSION}

ET was developed to better locate tumurs of the gastrointestinal tract and numerous studies confirm its clinical effectiveness $[6,48-54]$. Scientific societies (ASGE and ESGE) recommend the routine use of this procedure $[3,6]$. The results of tests in the evaluation of lymph node detection after the application of the tattoo, however, are ambiguous [49, 50, 55-60]. Correct 
Table 1. Studies reporting complications after using endoscopic tatooing technique

\begin{tabular}{|c|c|c|c|c|}
\hline Year & Author & Dye & Application & Complications \\
\hline 2017 & $\begin{array}{l}\text { Gonzalez-Tallon } \\
\text { et al. } .^{34}\end{array}$ & Spot ${ }^{\oplus}$ & Stomach & Gastric laceration \\
\hline 2017 & Awsaj et al. ${ }^{39}$ & Spot ${ }^{\oplus}$ & Colon & Liver abscess \\
\hline 2014 & Bang et al. ${ }^{36}$ & Indian ink & Colon & Colonic abscess \\
\hline 2012 & Chen et al. ${ }^{46}$ & Indian ink & $\begin{array}{l}\text { Small } \\
\text { intestine }\end{array}$ & Mesenteric air embolism \\
\hline 2011 & Marques et al. ${ }^{40}$ & Spot $^{\oplus}$ & Rectum & Rectal intramural hematoma \\
\hline 2006 & Singh et al. ${ }^{38}$ & Indian ink & Colon & Peritonitis \\
\hline 2003 & Gianom et al. ${ }^{45}$ & Indian ink & Colon & Retroperitoneal perforation \\
\hline 2003 & $\begin{array}{l}\text { Bahadursingh } \\
\text { et al. } .^{44}\end{array}$ & Indian ink & Colon & $\begin{array}{l}\text { Inadvertent transmural } \\
\text { tattoo simulating infarction } \\
\text { of small bowel }\end{array}$ \\
\hline 2000 & Alba et al. ${ }^{37}$ & Indian ink & Colon & Rectus muscle abscess \\
\hline 1999 & Dell'Abate et al. ${ }^{41}$ & Indian ink & Colon & Inflammatory pseudotumour \\
\hline 1999 & Gopal et al. ${ }^{43}$ & Indian ink & Colon & $\begin{array}{l}\text { Idiopathic inflammatory } \\
\text { bowel disease }\end{array}$ \\
\hline 1991 & Park et al. ${ }^{47}$ & Indian ink & Colon & $\begin{array}{l}\text { Colonic abscess and } \\
\text { peritonitis }\end{array}$ \\
\hline 1991 & Coman et al. ${ }^{42}$ & Indian ink & Colon & $\begin{array}{l}\text { Adipose tissue necrosis and } \\
\text { inflammatory pseudotumour }\end{array}$ \\
\hline
\end{tabular}

identification of a large number of LN makes it possible to detect potential metastases. Many studies have shown an increased number of LN after application of the tattoo. Bartels demonstrated the effectiveness of endoscopic tattoos for the evaluation of lymph nodes [49], results that were confirmed ia study by Aldecoa [50]. Keller's retrospective review confirmed the effectiveness of tattoo rectal lesions. In $5-8 \%$ of probably benign polyps, the presence of invasive cancer was reported. Without performing an endoscopic tattoo, there is no other possibility of licking the place of polypectomy of a given change? [61].

Endoscopic tattoo is a safe method with a low percentage of complications.

\section{CONCLUSIONS}

Studies confirm the benefits and safety of the ET procedure. Severe adverse events and complications have not been described as common. Many dyes are currently available, and the most commonly used and recommended are: Indian ink, Spot ${ }^{\circledR}$ dye, indocyanine green, methylene blue and indigocarmine. The administration of certain dyes, such as indocyanine green, can be used for intraoperative evaluation of lymphatic drainage and sentinel lymph nodes. The use of endoscopic tattooing is a technique recommended by many scientific societies, and is gradually becoming a standard procedure before a planned endoscopic or surgical treatment.

\section{Conflict of interest}

The authors declare no conflict of interest.

\section{Financial disclosure}

No funding was received for the study.

\section{REFERENCES}

1. Elarini T, Wexner SD, Isenberg GA. The need for standardization of colonoscopic tattooing of colonic lesions. Dis Colon Rectum. 2015; 58(2): 264-7.

2. Ponsky JL, King JF. Endoscopic marking of colonic lesions. Gastrointest Endosc. 1975; 22(1): 42-3.

3. Ferlitsch M, Moss A, Hassan C, et al. Colorectal polypectomy and endoscopic mucosal resection (EMR): European Society of Gastrointestinal Endoscopy (ESGE) Clinical Guideline. Endoscopy. 2017 Mar; 49(3): 270-297. doi: 10.1055/s-0043-102569. Epub 2017 Feb 17. PMID: 28212588.

4. Conaghan PJ, Maxwell-Armstrong CA, Garrioch MV, Hong L, Acheson AG. Leaving a mark: the frequency and accuracy of tattooing prior to laparoscopic colorectal surgery. Colorectal Dis. 2011; 13(10): 1184-7.

5. Aboosy N, Mulder CJ, Berends FJ, Meijer JW, Sorge AA. Endoscopic tattoo of the colon might be standardized to locate tumors intraoperatively. Rom J Gastroenterol. 2005; 14(3): 245-8.

6. ASGE Technology Committee, Kethu SR, Banerjee S, et al. Endoscopic tattooing. Gastrointest Endosc. 2010; 72(4): 681-5.

7. Fu KI, Fujii T, Kato S, et al. A new endoscopic tattooing technique for identifying the location of colonic lesions during laparoscopic surgery: a comparison with the conventional technique. Endoscopy. 2001; 33(8): $687-691$.

8. Sawaki A, Nakamura T, Suzuki T, et al. A two-step method for marking polypectomy sites in the colon and rectum. Gastrointest Endosc. 2003; 57(6): 735-737.

9. Nizam R, Siddiqi N, Landas SK, Kaplan DS, Holtzapple PG. Colonic tattooing with India ink: benefits, risks, and alternatives. Am J Gastroenterol. 1996; 91(9): 1804-1808.

10. Shatz BA, Weinstock LB, Swanson PE, Thyssen EP. Long-term safety of India ink tattoos in the colon. Gastrointest Endosc. 1997; 45(2): 153-156.

11. Hammond DC, Lane FR, Welk RA, Madura MJ, Borreson DK, Passinault WJ. Endoscopic tattooing of the colon. An experimental study. Am Surg. 1989; 55(7): 457-461.

12. Price N, Gottfried MR, Clary E, et al. Safety and efficacy of India ink and indocyanine green as colonic tattooing agents. Gastrointest Endosc. 2000; 51(4 Pt 1): 438-442.

13. Gress FG, Barawi M, Kim D, Grendell JH. Preoperative localization of a neuroendocrine tumor of the pancreas with EUS-guided fine needle tattooing. Gastrointest Endosc. 2002; 55(4): 594-597.

14. Farrell JJ, Sherrod A, Parekh D. EUS-guided fine-needle tattooing for preoperative localization of early pancreatic adenocarcinoma. Gastrointest Endosc. 2009; 69(1): 176-177.

15. Wiklund L, Basu S, Miclescu A, Wiklund P, Ronquist G, Sharma HS Neuro- and cardioprotective effects of blockade of nitric oxide action by administration of methylene blue. Ann N Y Acad Sci. 2007; 1122: 231-244.

16. Liu J, Huang P, Zheng Z, Chen T, Wei H. Modified methylene blue injection improves lymph node harvest in rectal cancer. ANZ J Surg. 2017; 87(4): 247-251.

17. Bara T Jr, Gurzu S, Jung I, Borz C, Banias L, Bara T. Sentinel node biospy using intravital blue dye: An useful technique for identification of skip metastases in gastric cancer. Medicine (Baltimore). 2019; 98(12): e14951.

18. Craik D, Khan D, Afifi R. The safety of intravenous indigo carmine to assess ureteric patency during transvaginal uterosacral suspension of the vaginal vault. Female Pelvic Medicine \& Reconstructive Surgery, 2009; 15(1): 11-15.

19. Retter J, Collet PH, Böcker U, Singer MV, Kähler G. Toluidinblau in der gastrointestinalen Endoskopie [Toluidin blue in gastrointestinal endoscopy]. Z Gastroenterol. 2010; 48(9): 1117-1119.

20. Rivet EB, Mutch MG, Ritter JH, et al. Ex vivo sentinel lymph node mapping in laparoscopic resection of colon cancer. Colorectal Dis. 2011; 13(11): 1249-1255.

21. Kane JM 3rd, Kahlenberg MS, Rodriguez-Bigas MA, Gibbs JF, Petrelli NJ. Intraoperative hepatic lymphatic mapping in patients with liver metastases from colorectal carcinoma. Am Surg. 2002; 68(9): 745-750.

22. Lee JY, Kim N. Diagnosis of Helicobacter pylori by invasive test: histology. Ann Transl Med. 2015; 3(1): 10.

23. Ortiz-Fernandez-Sordo J, Sami SS, Mansilla-Vivar R, et al. Evaluation of a novel infra-red endoscopy system in the assessment of early neoplasia in Barretts esophagus: pilot study from a single center [published correction appears in Dis Esophagus. 2018 Apr 1; 31(4):]. Dis Esophagus. 2018; 31(3): 10.1093/dote/dox137

24. Karakatsanis A, Christiansen PM, Fischer L, et al. The Nordic SentiMag trial: a comparison of super paramagnetic iron oxide (SPIO) nanoparticles versus $\mathrm{Tc}(99)$ and patent blue in the detection of sentinel 
node (SN) in patients with breast cancer and a meta-analysis of earlier studies. Breast Cancer Res Treat. 2016; 157(2): 281-294.

25. Teshome M, Wei C, Hunt KK, Thompson A, Rodriguez K, Mittendorf EA. Use of a Magnetic Tracer for Sentinel Lymph Node Detection in Early-Stage Breast Cancer Patients: A Meta-analysis. Ann Surg Oncol. 2016; 23(5): 1508-1514.

26. Houpeau JL, Chauvet MP, Guillemin F, et al. Sentinel lymph node identification using superparamagnetic iron oxide particles versus radioisotope: The French Sentimag feasibility trial. J Surg Oncol. 2016; 113(5): 501-507.

27. Ghilli M, Carretta E, Di Filippo F, et al. The superparamagnetic iron oxide tracer: a valid alternative in sentinel node biopsy for breast cancer treatment. Eur J Cancer Care (Engl). 2017; 26(4): 10.1111/ecc.12385

28. Piñero-Madrona A, Torró-Richart JA, de León-Carrillo JM, et al. Superparamagnetic iron oxide as a tracer for sentinel node biopsy in breast cancer: A comparative non-inferiority study. Eur J Surg Oncol. 2015; 41(8): 991-997.

29. Rubio IT, Diaz-Botero S, Esgueva A, et al. The superparamagnetic iron oxide is equivalent to the Tc99 radiotracer method for identifying the sentinel lymph node in breast cancer. Eur J Surg Oncol. 2015; 41(1): 46-51.

30. Thill M, Kurylcio A, Welter R, et al. The Central-European SentiMag study: sentinel lymph node biopsy with superparamagnetic iron oxide (SPIO) vs. radioisotope. Breast. 2014; 23(2): 175-179.

31. Douek M, Klaase J, Monypenny I, et al. Sentinel node biopsy using a magnetic tracer versus standard technique: the SentiMAG Multicentre Trial. Ann Surg Oncol. 2014; 21(4): 1237-1245.

32. Winter A, Woenkhaus J, Wawroschek F. A novel method for intraoperative sentinel lymph node detection in prostate cancer patients using superparamagnetic iron oxide nanoparticles and a handheld magnetometer: the initial clinical experience. Ann Surg Oncol. 2014; 21(13): 4390-4396.

33. ten Haken B. et al. (2010) Magnetic Detection of the Sentinel Lymph Node in Ex Vivo Tissue with Colorectal Cancer. In: Supek S., Sušac A. (eds) 17th International Conference on Biomagnetism Advances in Biomagnetism - Biomag2010. IFMBE Proceedings, vol 28. Springer, Berlin, Heidelberg

34. Gonzalez-Tallon AI, Rivero-Fernandez M, Calvo-Ramos I, et al. Hematemesis With Gastric Laceration After Tattooing a Polyp With Purified Carbon: A Review of the Literature. Gastroenterology Res. 2017; 10(1): 45-49.

35. Park SI, Genta RS, Romeo DP, Weesner RE. Colonic abscess and focal peritonitis secondary to india ink tattooing of the colon. Gastrointest Endosc. 1991; 37(1): 68-71.

36. Bang CS, Kim YS, Baik GH, Han SH. Colonic abscess induced by India ink tattooing. Korean J Gastroenterol. 2014; 64(1): 45-48.

37. Alba LM, Pandya PK, Clarkston WK. Rectus muscle abscess associated with endoscopic tattooing of the colon with India ink. Gastrointest Endosc. 2000; 52(4): 557-558.

38. Singh S, Arif A, Fox C, Basnyat P. Complication after pre-operative India ink tattooing in a colonic lesion. Dig Surg. 2006; 23(5-6): 303

39. Aawsaj YM, Kelly S, Slater B. Liver abscess secondary to an endoscopic tattoo in the colon. Ann R Coll Surg Engl. 2017; 99(2): e47-e48.

40. Marques I, Lagos AC, Pinto A, Neves BC. Rectal intramural hematoma: a rare complication of endoscopic tattooing. Gastrointest Endosc. 2011; 73(2): 366-367.

41. Dell'Abate P, Iosca A, Galimberti A, Piccolo P, Soliani P, Foggi E. Endoscopic preoperative colonic tattooing: a clinical and surgical complication. Endoscopy. 1999; 31(3): 271-273.

42. Coman E, Brandt LJ, Brenner S, Frank M, Sablay B, Bennett B. Fat necrosis and inflammatory pseudotumor due to endoscopic tattooing of the colon with india ink. Gastrointest Endosc. 1991; 37(1): 65-68.

43. Gopal DV, Morava-Protzner I, Miller HA, Hemphill DJ. Idiopathic inflammatory bowel disease associated with colonic tattooing with india ink preparation--case report and review of literature. Gastrointest Endosc. 1999; 49(5): 636-639.
44. Bahadursingh AM, Driver M, Koenig CL, Longo WE. Inadvertent transmural India ink tattooing simulating intestinal infarction. Am J Surg. 2003; 185(1): 88-89.

45. Gianom D, Hollinger A, Wirth HP. Darmperforation nach präoperativer kolonoskopischer Tuschemarkierung [Intestinal perforation after preoperative colonic tattooing with India ink]. Swiss Surg. 2003; 9(6): 307-310.

46. Chen N, Lamba R, Lee J, Lall C. Mesenteric air embolism following enteroscopic small bowel tattooing procedure. J Clin Imaging Sci. 2012; 2: 86.

47. Park SI, Genta RS, Romeo DP, Weesner RE. Colonic abscess and focal peritonitis secondary to India ink tattooing of the colon. Gastrointest Endosc. 1991; 37: 68-71.

48. Moss A, Bourke MJ, Pathmanathan N. Safety of colonic tattoo with sterile carbon particle suspension: a proposed guideline with illustrative cases. Gastrointest Endosc. 2011 Jul; 74(1): 214-8. doi: 10.1016/j. gie.2011.01.056. Epub 2011 Apr 8. PMID: 21481865

49. Bartels SAL, van der Zaag ES, Dekker E, Buskens CJ, Bemelman WA. The effect of colonoscopic tattooing on lymph node retrieval and sentinel lymph node mapping. Gastrointest Endosc. 2012; 76: 793-800. doi: 10.1016/j.gie.2012.05.005

50. Aldecoa I, et al. Endoscopic tattooing of early colon carcinoma enhances detection of lymph nodes most prone to harbor tumor burden, Surg Endosc. 2017; 31(2): 723-733. 10.1007/s00464-016-5026-3

51. Ellis KK, Fennerty MB. Marking and identifying colon lesions. Tattoos, clips, and radiology in imaging the colon. Gastrointest Endosc Clin N Am. 1997; 7: 401-411.

52. Yeung JMC, Maxwell-Armstrong C, Acheson AG. Colonic tattooing in laparoscopic surgery-making the mark? Colorectal Dis. 2009; 11: 527-530. doi: 10.1111/j.1463-1318.2008.01706.x

53. Beretvas RI, Ponsky J. Endoscopic marking: an adjunct to laparoscopic gastrointestinal surgery. Surg Endosc. 2001; 15: 1202-1203. doi: 10.1007/ s004640000304

54.Lacy AM, García-Valdecasas JC, Delgado S, Castells A, Taurá P, Piqué JM, Visa J. Laparoscopy-assisted colectomy versus open colectomy for treatment of non-metastatic colon cancer: a randomised trial. Lancet. 2002; 359: 2224-2229. doi: 10.1016/S0140-6736(02)09290-5

55. Dawson K, Wiebusch A, Thirlby RC. Preoperative tattooing and improved lymph node retrieval rates from colectomy specimens in patients with colorectal cancers. Arch Surg. 2010; 145: 826-830. doi: 10.1001/archsurg.2010.180

56. Kang J, Park HS, Kim I, Song Y, Baik SH, Sohn S-K, Lee KY. Effect of preoperative colonoscopic tattooing on lymph node harvest in T1 colorectal cancer. Int J Colorectal Dis. 2015; 30: 1349-1355. doi: 10.1007/ s00384-015-2308-5

57. Feo CV, Portinari M, Zuolo M, Targa S, Matarese VG, Gafà R, Forini E, Lanza G. Preoperative endoscopic tattooing to mark the tumour site does not improve lymph node retrieval in colorectal cancer: a retrospective cohort study. J Negat Results Biomed. 2015; 14: 9. doi: 10.1186/s12952-015-0027-7

58. Spatz H, Probst A, Oruzio D, Anthuber M, Messmann H, Arnholdt HM, Märkl B. Sentinel lymph node mapping as a side-effect of colonoscopic tattooing. Surg Endosc. 2010; 24: 589-593. doi: 10.1007/s00464-0090641-x

59. Viehl CT, Guller U, Hamel CT, Riehle HM, Plaass C, Marti WR, Oertli D, Zuber M. Carbon dye staining of sentinel lymph nodes facilitates microstaging of colon cancer patients. World J Surg. 2006; 30: 453-456. doi: 10.1007/s00268-005-0336-y

60. Cahill RA, Lindsey I, Cunningham C. Sentinel node mapping by colonic tattooing. Surg Endosc Other Interv Tech. 2010; 24: 2365-2366. doi: 10.1007/s00464-010-0941-1

61. Keller D, Jaffe J, Philp MM, Haluszka O, Khanna A. Should all endoscopically excised rectal polyps be tattooed? A plea for localization. Surg Endosc Other Interv Tech. 2012; 26: 3101-3105. 